\title{
New risk factors of postoperative complications in elective gastrointestinal surgery of elderly patients: a prospective cohort study
}

Kei Yokozuka, Koichi Tomita, Masashi Nakagawa, Itsuki Koganezawa, Shigeto Ochiai, Takahiro Gunji, Yosuke Ozawa, Kosuke Hikita, Toshimichi Kobayashi, Toru Sano, Satoshi Tabuchi, Naokazu Chiba, Eiji Hidaka and Shigeyuki Kawachi

\begin{abstract}
Background: Gastrointestinal surgery in elderly individuals presents unexpected postoperative complications. However, predicting postoperative complications in elderly patients undergoing gastrointestinal surgeries is challenging because of the lack of a reliable preoperative evaluation system. We aimed to prospectively evaluate three new preoperative assessment methods to predict the postoperative complications in elderly patients undergoing elective gastrointestinal surgery. Moreover, we aimed to identify new risk factors of postoperative complications in this patient group.

Methods: This prospective cohort study enrolled 189 patients (age $\geq 65$ years) who underwent elective gastrointestinal surgery at Tokyo Medical University Hachioji Medical Center between April 2017 and March 2019. Assessments performed preoperatively included the biological impedance analysis for evaluating the skeletal muscle mass, the SF-8 questionnaire for evaluating the subjective health-related quality of life, and the blood pressure/pulse wave test for assessing arteriosclerosis. The risk factors for Clavien-Dindo Grade $\geq$ III postoperative complications were assessed using these new evaluation methods.
\end{abstract}

Results: Clavien-Dindo Grade $\geq$ III postoperative complications were observed in 28 patients (14.8\%). Univariate and multivariate analyses identified male sex, low skeletal muscle mass, and cardio-ankle vascular index $\geq 10$ (arteriosclerosis) as significant independent risk factors of developing Grade $\geq$ III complications.

Conclusions: Male sex, low skeletal muscle mass, and arteriosclerosis were significant risk factors of postoperative complications in elderly patients undergoing elective gastrointestinal surgery. The obtained knowledge could be useful in identifying high-risk patients who require careful perioperative management.

Keywords: Arteriosclerosis, Elderly, Gastrointestinal surgery, Postoperative complication, Skeletal muscle

*Correspondence: skawachi@tokyo-med.ac.jp

Department of Digestive and Transplantation Surgery, Tokyo Medical University Hachioji Medical Center, 1163 Tatemachi, Tokyo 193-0998, Japan

\section{Background}

The number of elderly people has increased worldwide, especially in Japan. In 2014 , approximately $25.9 \%$ of the Japanese population were older than 65 years [1]. Furthermore, the average life expectancy of the Japanese 
population in 2015 was 80.5 years for men and 86.8 years for women, which were the highest worldwide [2].

Elderly patients have a higher incidence of postoperative complications than younger patients. The surgical indication of elective gastrointestinal (GI) surgery for elderly individuals has been determined based on standard preoperative evaluations, such as blood tests, physiological function tests, and performance status. However, unexpected postoperative complications can often occur in elderly patients, unlike in younger patients. Moreover, predicting postoperative complications in elderly patients undergoing gastrointestinal surgeries is challenging because of the lack of a reliable preoperative evaluation system.

This study prospectively evaluated three new preoperative tests to predict the postoperative complications of elective GI surgery in elderly patients. In addition, we aimed to identify new risk factors for developing postoperative complications.

\section{Methods}

This prospective cohort study consecutively enrolled 293 patients who had undergone elective GI surgery at Tokyo Medical University Hachioji Medical Center between April 2017 and March 2019. All patients were aged $\geq 65$ years. The procedures were approved by the institutional review board of Tokyo Medical University Hachioji Medical Center (H-164) and performed in accordance with the Helsinki declaration of 1975, as revised in 1983.Written informed consent was obtained from all patients.

In this study, we conducted the following three different evaluations: Biological impedance analysis (BIA) to measure and analyze the body composition; healthrelated quality of life (QOL) scale to evaluate the subjective mental and physical health; and the blood pressure/ pulse wave test to evaluate arteriosclerosis. These evaluations are very easy to perform and require approximately $10 \mathrm{~min}$. They can diagnose low skeletal muscle mass, decreases in QOL, and arteriosclerosis, respectively, which may cause postoperative GI complications. Interestingly, these conditions could not be evaluated by conventional preoperative examinations for GI surgery.

A total of 104 patients were excluded from this study because of missing data in any of the three evaluations. For BIA, patients with metal objects internally, such as a cardiac pacemaker or those who could not stand independently, were excluded. For the health-related QOL scale, those who could not respond to the questionnaires were excluded. Regarding the blood pressure pulse wave tests, patients in whom the limb blood pressure could not be measured because of a history of hemodialysis or breast cancer surgery or because of their inability to extend their limbs were excluded. Finally, 189 patients were enrolled in this study (Fig. 1). The 5 -item modified frailty index (5-mFI) was also calculated for all patients to compare these three evaluations. The $5-\mathrm{mFI}$ is a valid predictor of postoperative outcomes, consisting of diabetes mellitus, congestive heart failure, hypertension, chronic obstructive pulmonary disease, and functional health status [3, 4].

\section{Biological impedance analysis}

The multifrequency body composition analyzer InBody 770 (Biospace Co., Seoul, Korea) was used. This device can measure body water, muscle, and fat using the impedance method. In this study, the skeletal muscle weight, skeletal muscle index (SMI), body fat $(\mathrm{kg})$, and body cell mass $(\mathrm{kg})$ were measured. SMI values $<7.0 \mathrm{~kg} /$ $\mathrm{m}^{2}$ for men and $<5.7 \mathrm{~kg} / \mathrm{m}^{2}$ for women were considered abnormal, based on the criteria of the Asian Working Group on Sarcopenia [5].

\section{Health-related QOL scale by SF-8}

The health-related QOL scale was investigated using the Medical Outcomes Study 8-item Short-Form Health Survey $\left(\mathrm{SF}-8^{\mathrm{TM}}\right)$ questionnaire [6]. The $\mathrm{SF}-8$ is a measure of comprehensive health-related QOL. SF-8 measures the following two components: the physical and the mental component summary. The cutoff value of SF- 8 was defined as $<25$ th percentile of the normal distribution, and patients with lower scores than the cutoff value were diagnosed as having abnormal subjective QOL.

\section{Blood pressure/pulse wave test}

The cardio-ankle vascular index (CAVI) was measured using the blood pressure pulse wave analyzer VaSera

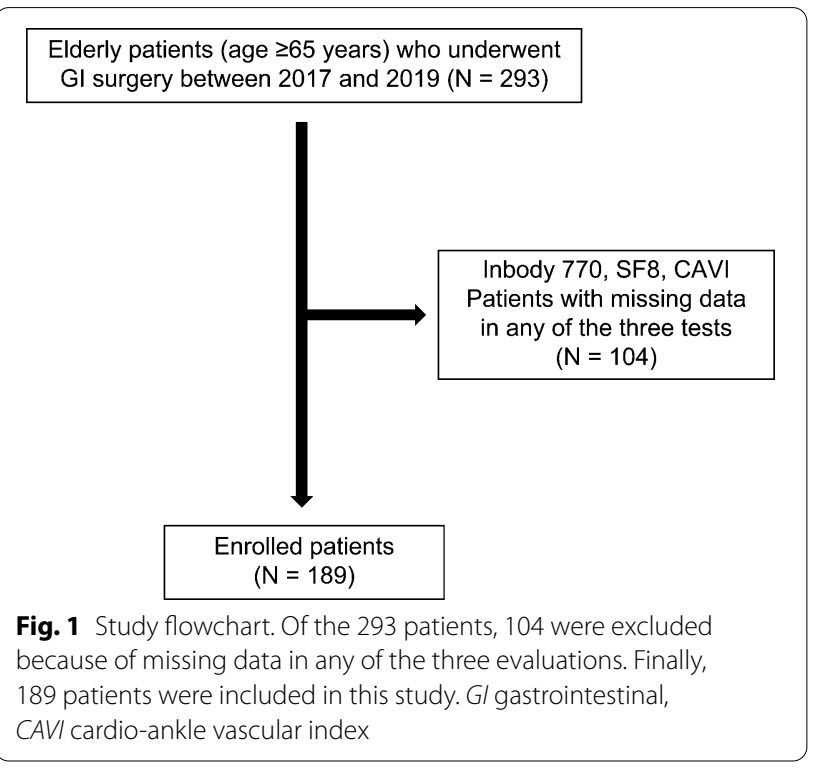


VS-2000 (Fukuda Denshi Tokyo Nishi Sales Co., Ltd., Tokyo, Japan) [7]. In general, the CAVI is measured by placing a heart sound microphone around the cardiac apex and a manchette around the limbs, and it is calculated using an algorithm [8]. The CAVI is considered a good index of arteriosclerosis [9] and is positively correlated with arteriosclerosis parameters [10]. There is no standard cutoff CAVI value in patients who had undergone GI surgery. In this study, CAVI scores $\geq 10.0$ were considered abnormal (arteriosclerosis) based on the preliminary study (data not shown). As no apparent sex difference was reported for the CAVI values, the analysis was not stratified by sex.

\section{Postoperative complications}

The severity of postoperative complications was graded using the Clavien-Dindo classification [11, 12]. This is a representative grading system of postoperative complications used worldwide. We aimed to predict the complications of Grade $\geq$ III, because they require invasive treatments. Pulmonary complications include pneumonia, atelectasis, and hypoxia requiring reintubation.

\section{Statistical analyses}

All statistical analyses were performed using IBM SPSS Statistics for Windows, version 26.0, (IBM Corp., Armonk, NY, USA). Continuous variables are expressed as means \pm standard deviations or medians with ranges. The Mann-Whitney U-test was used for their comparisons. Categorical variables were compared using the Chisquare or Fisher's exact test, as required. Throughout our analysis, statistical tests were two-tailed, and the significance was set at $\mathrm{p}<0.05$. A multivariate regression analysis was performed using a logistic regression analysis with forward likelihood ratio selection.

\section{Results}

\section{Patient characteristics}

The patient characteristics are summarized in Table 1. Esophageal surgery, gastrectomy, gastric bypass, colectomy, rectectomy, stoma closure, and appendectomy were performed in two, 67, seven, 77, 27, nine, and three cases, respectively. Among our patients, 23 (12.1\%), 21 (11.1\%), and six (3.0\%) had Clavien-Dindo Grade II (requiring drug therapy, such as antibiotics), III (requiring invasive therapy), and IV complications (involving organ dysfunction and requiring admission to the intensive care unit), respectively. A Grade $\mathrm{V}$ complication (death) occurred in one patient $(0.5 \%)$. Twenty-eight patients $(14.8 \%)$ had Grade $\geq$ III complications, including abdominal abscess, pulmonary complications, ileus, pancreatic fistula, and anastomotic leakage in nine, seven, six, six, and three patients, respectively. Some patients had multiple complications.

\section{Univariate and multivariate analyses}

The results of the univariate and multivariate analyses evaluating the relationship between the parameters obtained using the new evaluation techniques and Grade $\geq$ III complications are presented in Table 2. In the univariate analysis, there was a significant association of Grade $\geq$ III complications with male sex $(p=0.005)$, hypertension $(\mathrm{p}=0.033)$, abnormal SMI $(\mathrm{p}=0.007)$, and CAVI $\geq 10(p=0.004)$. Using these factors in the multivariate logistic regression analysis, male sex (odds ratio [OR], 5.51; 95\% confidence interval [CI] 1.55-19.57; $\mathrm{p}=0.008$ ), abnormal SMI (OR, 2.78; 95\% CI 1.16-6.71; $\mathrm{p}=0.023$ ), and $\mathrm{CAVI} \geq 10$ (OR, 2.81; 95\% CI 1.18-6.67; $\mathrm{p}=0.019)$ remained independent risk factors of postoperative complications. The abnormal SMI indicated low skeletal muscle mass, and CAVI $\geq 10$ indicated arteriosclerosis. The 5 -item modified frailty index did not show a significant difference for Grade $\geq$ III postoperative complications in these subjects.

\section{Discussion}

The risk factor of postoperative complications in elective GI surgery, especially of elderly patients, has not been well established. For example, the body mass index or laparoscopic conversion, which has been considered the risk factors, were not proved as the risk factors of postoperative complications based on the previous reports [13, 14]. According to the recent report of Geriatric Oncology Surgical Assessment and Functional rEcovery after Surgery (GOSAFE) study, which included 997 multinational patients, the frailty is frequent in older patients undergoing cancer surgery [15]. The present study evaluated three new preoperative tests for predicting postoperative complications in elderly patients who had undergone elective GI surgery, and male sex, low skeletal muscle mass, and arteriosclerosis were found to be independent risk factors of postoperative complication.

Although the study included elderly patients aged $\geq 65$ years, age did not significantly impact their condition. Previous systematic reviews and literature findings indicated that age might not be significantly associated with postoperative complications [16], which was consistent with our findings. A possible explanation may be that surgery or preoperative management in this study would be performed more attentively in older patients.

In our study, male sex was found to be a significant risk factor for developing postoperative complications. Moreover, women had more prominent hormonal and cell-mediated immune responses compared to men [17]. Conversely, men had higher testosterone and lower 
Table 1 Characteristics of the study population

\begin{tabular}{|c|c|c|c|}
\hline & $\begin{array}{l}\text { All cases } \\
\mathrm{N}=189^{*}\end{array}$ & $\begin{array}{l}\text { Upper Gl } \\
N=76\end{array}$ & $\begin{array}{l}\text { Lower Gl } \\
\mathrm{N}=119\end{array}$ \\
\hline \multicolumn{4}{|l|}{ General background } \\
\hline Age (years) & $75(65-95)$ & $75(65-92)$ & $75(65-95)$ \\
\hline \multicolumn{4}{|l|}{ Sex } \\
\hline Male & $125(66.1 \%)$ & $54(71.0 \%)$ & $72(62.0 \%)$ \\
\hline Female & $64(33.8 \%)$ & $22(28.9 \%)$ & $44(37.9 \%)$ \\
\hline \multicolumn{4}{|l|}{ Comorbidity } \\
\hline Hypertension & $100(52.9 \%)$ & $42(55.2 \%)$ & $60(51.7 \%)$ \\
\hline Diabetes mellitus & $47(24.8 \%)$ & $16(21.0 \%)$ & $30(25.8 \%)$ \\
\hline Hyperlipidemia & $34(17.9 \%)$ & $16(21.0 \%)$ & $17(14.6 \%)$ \\
\hline Cardiovascular & $26(13.7 \%)$ & $11(14.4 \%)$ & $16(13.7 \%)$ \\
\hline Cerebrovascular & $18(9.5 \%)$ & $5(6.5 \%)$ & $12(10.3 \%)$ \\
\hline Renal & $11(5.8 \%)$ & $3(3.9 \%)$ & $8(6.8 \%)$ \\
\hline Hemodialysis & $5(2.6 \%)$ & $0(0.0 \%)$ & $5(4.3 \%)$ \\
\hline Respiratory & $4(2.1 \%)$ & $3(3.9 \%)$ & $1(0.8 \%)$ \\
\hline 5-item modified frailty index & $0.98 \pm 0.889$ & $0.99 \pm 0.893$ & $0.97 \pm 0.864$ \\
\hline \multicolumn{4}{|l|}{ Surgical information } \\
\hline \multicolumn{4}{|l|}{ Organ } \\
\hline Esophagectomy & & $2(2.6 \%)$ & \\
\hline Gastrectomy & & $67(88.2 \%)$ & \\
\hline Distal & & $37(48.6 \%)$ & \\
\hline Total & & $14(18.4 \%)$ & \\
\hline Proximal & & $8(10.5 \%)$ & \\
\hline Partial & & $8(10.5 \%)$ & \\
\hline Bypass & & $7(9.2 \%)$ & \\
\hline Colectomy & & & $77(64.7 \%)$ \\
\hline Rectectomy & & & $27(22.7 \%)$ \\
\hline Small intestine & & & $1(0.8 \%)$ \\
\hline Stoma closure & & & $9(7.7 \%)$ \\
\hline lleostomy/colostomy & & & $2(1.7 \%)$ \\
\hline Appendectomy & & & $3(2.5 \%)$ \\
\hline \multicolumn{4}{|l|}{ Disease } \\
\hline Malignant & $168(88.8 \%)$ & 68 (89.4\%) & $106(91.3 \%)$ \\
\hline Benign & $21(11.1 \%)$ & $8(10.5 \%)$ & $10(8.6 \%)$ \\
\hline \multicolumn{4}{|l|}{ Approach } \\
\hline Open laparotomy & $78(41.2 \%)$ & $53(69.7 \%)$ & $33(28.4 \%)$ \\
\hline Laparoscopic & $111(58.7 \%)$ & $23(30.2 \%)$ & $83(71.5 \%)$ \\
\hline \multicolumn{4}{|l|}{ New preoperative evaluation } \\
\hline \multicolumn{4}{|l|}{ InBody 770} \\
\hline $\mathrm{BMI}\left(\mathrm{kg} / \mathrm{m}^{2}\right)$ & $22.5(14.6-37.6)$ & $21.9(14.6-32.8)$ & $22.8(15.9-37.6)$ \\
\hline \multicolumn{4}{|l|}{$\mathrm{SMI}\left(\mathrm{kg} / \mathrm{m}^{2}\right)$} \\
\hline Men & $7.1(4.1-10.2)$ & $7.0(4.1-10.2)$ & $7.10(5.20-9.20)$ \\
\hline Women & $5.8(4.2-10.4)$ & $5.8(4.8-7.8)$ & $5.8(4.2-10.4)$ \\
\hline Abnormal & $78(41.2 \%)$ & $35(46.0 \%)$ & $45(38.7 \%)$ \\
\hline Body fat (\%) & $26.0(7.1-47.0)$ & $24.5(7.1-43.9)$ & $26.4(12.1-47.0)$ \\
\hline Body cell mass (kg) & $26.7(16.8-42.2)$ & $26.7(16.8-42.2)$ & $26.9(17.5-38.2)$ \\
\hline \multicolumn{4}{|l|}{ SF-8 } \\
\hline \multicolumn{4}{|l|}{ PCS score } \\
\hline Men & $47.4(18.6-59.2)$ & $48.0(19.2-57.5)$ & $46.4(18.6-59.2)$ \\
\hline
\end{tabular}


Table 1 (continued)

\begin{tabular}{|c|c|c|c|}
\hline & $\begin{array}{l}\text { All cases } \\
N=189^{*}\end{array}$ & $\begin{array}{l}\text { Upper Gl } \\
N=76\end{array}$ & $\begin{array}{l}\text { Lower Gl } \\
N=119\end{array}$ \\
\hline Women & $48.4(19.6-58.8)$ & $47.3(19.6-57.5)$ & $49.0(23.6-58.8)$ \\
\hline Abnormal & $43(22.7 \%)$ & $13(17.1 \%)$ & $31(26.7 \%)$ \\
\hline \multicolumn{4}{|l|}{ MCS score } \\
\hline Men & $49.3(19.9-64.6)$ & $50.4(26.6-64.6)$ & $48.9(19.9-64.6)$ \\
\hline Women & $48.0(24.4-57.3)$ & $48.6(29.7-55.3)$ & $46.5(24.4-57.3)$ \\
\hline Abnormal & $74(39.1 \%)$ & $27(35.5 \%)$ & $49(42.2 \%)$ \\
\hline \multicolumn{4}{|l|}{ Blood pressure/pulse wave test } \\
\hline CAVI & $9.31 \pm 1.862$ & $9.23 \pm 1.879$ & $9.36 \pm 1.856$ \\
\hline Abnormal $(\geq 10)$ & $63(33.3 \%)$ & $24(31.5 \%)$ & $41(35.3 \%)$ \\
\hline \multicolumn{4}{|l|}{ Surgical outcome } \\
\hline Operative time (min) & $244.0(65-788)$ & $261.5(100-587)$ & $217.0(65-788)$ \\
\hline Blood loss (g) & $40.0(10-2995)$ & $66.5(10-1635)$ & $20.0(10-2995)$ \\
\hline \multicolumn{4}{|l|}{ Postoperative complication } \\
\hline \multicolumn{4}{|l|}{ Clavien-Dindo Grade } \\
\hline । & $6(3.1 \%)$ & $2(2.6 \%)$ & $4(3.4 \%)$ \\
\hline$\|$ & $23(12.1 \%)$ & $12(15.7 \%)$ & $11(9.4 \%)$ \\
\hline III & $21(11.1 \%)$ & $10(13.1 \%)$ & $12(10.3 \%)$ \\
\hline IV & $6(3.2 \%)$ & $3(3.9 \%)$ & $3(2.5 \%)$ \\
\hline V & $1(0.5 \%)$ & $0(0.0 \%)$ & $1(0.9 \%)$ \\
\hline$\geq I I I$ & $28(14.8 \%)$ & $13(17.1 \%)$ & $16(13.7 \%)$ \\
\hline \multicolumn{4}{|c|}{ Type of complication (Grade $\geq I I I)$} \\
\hline Abdominal abscess & $9(4.7 \%)$ & $5(6.5 \%)$ & $4(3.4 \%)$ \\
\hline Pulmonary complications & $7(3.7 \%)$ & $5(6.5 \%)$ & $2(1.7 \%)$ \\
\hline lleus & $6(3.1 \%)$ & $0(0.0 \%)$ & $6(5.1 \%)$ \\
\hline Pancreatic fistula & $6(3.1 \%)$ & $5(6.5 \%)$ & $1(0.9 \%)$ \\
\hline Anastomotic leakage & $3(1.5 \%)$ & $2(2.6 \%)$ & $1(0.9 \%)$ \\
\hline Anastomotic bleeding & $1(0.5 \%)$ & $0(0.0 \%)$ & $1(0.9 \%)$ \\
\hline Anastomotic stenosis & $1(0.5 \%)$ & $1(1.3 \%)$ & $0(0.0 \%)$ \\
\hline Cerebral infarction & $1(0.5 \%)$ & $1(1.3 \%)$ & $0(0.0 \%)$ \\
\hline Intestinal ischemia & $1(0.5 \%)$ & $0(0.0 \%)$ & $1(0.9 \%)$ \\
\hline Myocardial infarction & $1(0.5 \%)$ & $0(0.0 \%)$ & $1(0.9 \%)$ \\
\hline Postoperative stay (days) & $12(3-197)$ & $13(6-93)$ & $11(3-197)$ \\
\hline
\end{tabular}

Continuous variables are expressed as mean values \pm standard deviations or medians with ranges Categorical variables are expressed as number of patients

$B M I$ body mass index, SMI skeletal muscle mass index, $P C S$ physical component summary, $M C S$ mental component summary, $A B I$, ankle-brachial pressure index, $C A V I$ cardio-ankle vascular index, Gl gastrointestinal

a Six cases were duplications of upper and lower Gl

estradiol levels during surgery and other interventions than women, which may be a factor involved in immunosuppression and may contribute to increased risk for postoperative complications [18].

In elderly patients, the combination of age-related decrease in muscle mass (primary sarcopenia) and disease-related loss of activity or muscle loss because of malnutrition (secondary sarcopenia) has been reported to be a factor that affects the prognosis of various GI surgical interventions, such as living donor liver transplantation
[19], hepatectomy [20], and pancreatectomy [21]. In BIA, body fat mass was also reported to predict postoperative complications [22], as body fat makes surgery difficult and increases the amount of blood loss, surgical time, and wound infection risk. Nonetheless, only SMI was found to be a significant risk factor in our study.

Concerning the health-related QOL scale, assessing a patient's preoperative status using SF-36 may have a greater value, as the preoperative status could be an independent risk factor of postoperative complications in 
Table 2 Analyses of clinical characteristics of patients with postoperative complications assessed using the Clavien-Dindo classification

\begin{tabular}{|c|c|c|c|c|c|}
\hline \multicolumn{4}{|c|}{ Univariate analysis } & \multicolumn{2}{|c|}{ Multivariate analysis } \\
\hline Grade $\leq \|$ & Grade $\geq I I I$ & p-value & Odds ratio $(95 \% \mathrm{Cl})$ & $p$-value & Odds ratio $(95 \% \mathrm{Cl})$ \\
\hline$N=161$ & $N=28$ & & & & \\
\hline
\end{tabular}

General background

Age

\begin{tabular}{|c|c|c|c|c|c|c|}
\hline Years & $75.0(65-95)$ & 76.5 (67-92) & 0.206 & & & \\
\hline$\geq 80$ years & $36(22.4 \%)$ & $11(39.3 \%)$ & 0.056 & $2.25(0.97-5.23)$ & 0.088 & \\
\hline \multicolumn{7}{|l|}{ Sex } \\
\hline Male & $100(62.1 \%)$ & 25 (89.3\%) & 0.005 & $5.08(1.47-17.55)$ & 0.008 & $5.51(1.55-19.57)$ \\
\hline \multicolumn{7}{|l|}{ Comorbidity } \\
\hline Hypertension & $80(49.7 \%)$ & $20(71.4 \%)$ & 0.033 & $2.53(1.05-6.08)$ & 0.094 & \\
\hline Diabetes mellitus & $41(25.5 \%)$ & $6(21.4 \%)$ & 0.648 & & & \\
\hline Hyperlipidemia & $29(18.0 \%)$ & $5(17.9 \%)$ & 0.984 & & & \\
\hline Cardiovascular & $22(13.7 \%)$ & $4(14.3 \%)$ & 0.563 & & & \\
\hline Cerebrovascular & $14(8.7 \%)$ & $4(14.3 \%)$ & 0.266 & & & \\
\hline Renal & $8(5.0 \%)$ & $3(10.7 \%)$ & 0.211 & & & \\
\hline Hemodialysis & $4(2.5 \%)$ & $1(3.6 \%)$ & 0.556 & & & \\
\hline Respiratory & $2(1.2 \%)$ & $2(7.1 \%)$ & 0.105 & & & \\
\hline \multicolumn{7}{|c|}{ 5-item modified frailty index } \\
\hline$\geq 2$ & 35 (21.9\%) & $10(35.7 \%)$ & 0.113 & & & \\
\hline \multicolumn{7}{|l|}{ Disease } \\
\hline Malignant & $143(88.8 \%)$ & $25(89.3 \%)$ & 0.621 & & & \\
\hline \multicolumn{7}{|l|}{ nBody 770} \\
\hline BMI $\left(\mathrm{kg} / \mathrm{m}^{2}\right)$ & $22.5(14.6-37.6)$ & $21.9(15.7-26.5)$ & 0.215 & & & \\
\hline SMI & $6.6(4.1-10.4)$ & $6.55(5.3-8.3)$ & 0.538 & & & \\
\hline Abnormal & $60(37.3 \%)$ & $18(64.3 \%)$ & 0.007 & $3.03(1.31-6.99)$ & 0.023 & $2.78(1.16-6.71)$ \\
\hline Body fat (\%) & $26.3(7.1-47.0)$ & $25.1(9.0-40.0)$ & 0.569 & & & \\
\hline Body cell mass (kg) & $26.8(16.8-42.2)$ & $26.6(22.1-34.3)$ & 0.871 & & & \\
\hline \multicolumn{7}{|l|}{ F-8 } \\
\hline PCS score & $47.9(18.6-59.2)$ & $46.5(19.2-55.8)$ & 0.295 & & & \\
\hline Abnormal & $34(23.4 \%)$ & $9(36.0 \%)$ & 0.182 & & & \\
\hline MCS score & $48.8(24.4-64.6)$ & $51.6(20.0-64.7)$ & 0.291 & & & \\
\hline Abnormal & $65(44.8 \%)$ & $9(36.0 \%)$ & 0.411 & & & \\
\hline \multicolumn{7}{|c|}{ Blood pressure/pulse wave test } \\
\hline \multicolumn{7}{|l|}{ CAVI } \\
\hline Abnormal & 47 (29.2\%) & $16(57.1 \%)$ & 0.004 & $3.23(1.42-7.36)$ & 0.019 & $2.81(1.18-6.67)$ \\
\hline
\end{tabular}

Continuous variables are expressed as mean values \pm standard deviations or medians with ranges

Categorical variables are expressed as number of patients

$B M I$ body mass index, SMI skeletal muscle mass index, PCS physical component summary, MCS mental component summary, CAVI cardio-ankle vascular index, Cl confidence interval

patients undergoing major GI surgeries, as suggested by a previous report [23]. As the mental and physical health of the patients is largely perceived by them, there may have been a discrepancy between the patients' actual condition and their answers to the self-reported questionnaire.

To our knowledge, there is currently no study directly elucidating the relationship between arteriosclerosis and GI surgical complications. The CAVI, which was newly introduced in the present study, is an index of arteriosclerosis in blood pressure/pulse wave test. Interestingly, the ankle-brachial pressure index is an index of peripheral arteriosclerosis, whereas the CAVI is an index of visceral arteriosclerosis. Our results showed that patients with diabetes mellitus or chronic kidney disease had higher rates of abnormal CAVIs, indicating higher arteriosclerosis rates. The visceral arteriosclerosis might be related to 
some postoperative complications after GI surgery, such as ileus, pancreatic fistula, anastomotic leakage, bleeding, stenosis, cerebral infarction, intestinal ischemia, and myocardial infarction. Moreover, CAVI was previously reported to be an independent risk factor for frailty [24], which may cause additional complications.

There were several limitations in this study. First, this was a single-institutional study with limited sample size; thus, a multi-institutional study may be needed to confirm our results. Moreover, patients with poor general conditions (inability to stand or answer the questionnaire) could not be evaluated using the assessment tools used in this study; thus, other evaluation methods will be needed for them.

\section{Conclusions}

In elderly patients undergoing elective GI surgery, male sex, low skeletal muscle mass, and arteriosclerosis were significant risk factors of presenting postoperative complications. The knowledge of these risk factors could be useful in identifying high-risk patients requiring careful perioperative management.

\section{Abbreviations}

GI: Gastrointestinal; BIA: Biological impedance analysis; SMI: Skeletal muscle index; QOL: Health-related quality of life; CAVI: Cardio-ankle vascular index.

\section{Acknowledgements}

Not applicable.

\section{Authors' contributions}

SK: project development, data collection and critical revision of the manuscript. KY and KT: data collection and analysis, manuscript writing. MN, IK, SO, $\mathrm{TG}, \mathrm{YO}, \mathrm{KH}, \mathrm{TK}, \mathrm{TS}, \mathrm{ST}, \mathrm{NC}$, and EH: data collection and critical revision of the manuscript. All authors read and approved the final manuscript.

\section{Funding}

This study was funded by Grant-in-Aid for Scientific Research (16K10440) and Daiwa Securities Co., Ltd (46th Research Grant).

\section{Availability of data and materials}

All data generated or analyzed during this study are included in this published article.

\section{Declarations}

Ethics approval and consent to participate

The procedures were approved by the institutional review board of Tokyo Medical University Hachioji Medical Center (H-164).Written informed consent was obtained from all patients.

\section{Consent for publication}

Not applicable.

\section{Competing interests}

The authors declare that they have no competing interests.
References

1. Ministry of Internal Affairs and Communication SB. Statistics Bureau/ Japan Statistical Yearbook 2016_Chapter 2 Population and Households. 2016. http://www.stat.go.jp/english/data/nenkan/1431-02.htm. Accessed 25 Nov 2020

2. World Health Organization. World Health Statistics 2016: monitoring health for the SDGs. WHO; 2016. 2017. https://www.who.int/gho/publi cations/world_health_statistics/2016/en/. Accessed 25 Nov 2020.

3. Chimukuangara M, Helm MC, Frelich MJ, Bosler ME, Rein LE, Szabo A, et al. A 5-item frailty index based on NSQIP data correlates with outcomes following paraesophageal hernia repair. Surg Endosc. 2017; 31:2509-19.

4. Al-Khamis A, Warner C, Park J, Marecik S, Davis N, Mellgren A, et al. Modified frailty index predicts early outcomes after colorectal surgery: an ACS-NSQIP study. Colorectal Dis 2019;21:1192-205.

5. Chen LK, Liu LK, Woo J, Assantachai P, Auyeung TW, Bahyah KS, et al. Sarcopenia in Asia: Consensus report of the Asian Working Group for sarcopenia. J Am Med Dir Assoc. 2014;15:95-101.

6. Tokuda Y, Okubo T, Ohde S, Jacobs J, Takahashi O, Omata F, et al. Assessing items on the SF-8 Japanese version for health-related quality of life: a psychometric analysis based on the nominal categories model of item response theory. Value Health. 2009;12:568-73.

7. Asmar R. Principles and usefulness of the cardio-ankle vascular index (CAVI): a new global arterial stiffness index. Eur Heart J. 2017;19:B4-10.

8. Yambe T, Yoshizawa M, Saijo Y, Yamaguchi T, Shibata M, Konno S, et al. Brachio-ankle pulse wave velocity and cardio-ankle vascular index (CAVI). Biomed Pharmacother. 2004;58:S95-8.

9. Shirai K, Utino J, Otsuka K, Takata M. A novel blood pressure-independent arterial wall stiffness parameter; cardio-ankle vascular index (CAVI). J Atheroscler Thromb. 2006;13:101-7.

10. Shirai K, Utino J, Saiki A, Endo K, Ohira M, Nagayama D, et al. Evaluation of blood pressure control using a new arterial stiffness parameter, cardioankle vascular index (CAVI). Curr Hypertens Rev. 2013;9:66-75.

11. Clavien PA, Barkun J, de Oliveira ML, Vauthey JN, Dindo D, Schulick RD, et al. The Clavien-Dindo classification of surgical complications: five-year experience. Ann Surg. 2009;250:187-96.

12. Dindo D, Demartines N, Clavien PA. Classification of surgical complications: a new proposal with evaluation in a cohort of 6336 patients and results of a survey. Ann Surg. 2004;240:205-13.

13. EuroSurg Collaborative. Body mass index and complications following major gastrointestinal surgery: a prospective, international cohort study and meta-analysis. Colorectal Dis. 2018;20:215-25.

14. 2017 and 2015 European Society of Coloproctology (ESCP) Collaborating Groups. The impact of conversion on the risk of major complication following laparoscopic colonic surgery: an international, multicentre prospective audit. Colorectal Dis. 2018;20(Suppl 6):69-89.

15. Montroni I, Rostoft S, Spinelli A, Van Leeuwen BL, Ercolani G, Saur NM, et al. GOSAFE-Geriatric Oncology Surgical Assessment and Functional rEcovery after Surgery: early analysis on 977 patients. J Geriatr Oncol. 2020;11:244-55.

16. Miyazaki Y, Kokudo T, Amikura K, Kageyama Y, Takahashi A, Ohkohchi N, et al. Age does not affect complications and overall survival rate after pancreaticoduodenectomy: single-center experience and systematic review of literature. Biosci Trends. 2016;10:300-6.

17. Grossman CJ. Interactions between the gonadal steroids and the immune response. Science. 1985;227:257-61.

18. Angele MK, Ayala A, Monfils BA, Cioffi WG, Bland KI, Chaudry IH. Testosterone and/or low estradiol: normally required but harmful immunologically for males after trauma-hemorrhage. J Trauma. 1998;44:78-85.

19. Ogawa K, Fujimoto Y, Ogura Y, Hata K, Ito T, Tomiyama K, et al. Impact of sarcopenia on survival in patients undergoing living donor liver transplantation. Am J Transplant. 2013;13:1549-56.

20. Harimoto N, Shirabe K, Yamashita Yl, Ikegami T, Yoshizumi T, Soejima Y, et al. Sarcopenia as a predictor of prognosis in patients following hepatectomy for hepatocellular carcinoma. Br J Surg. 2013;100:1523-30.

21. Okumura S, Kaido T, Hamaguchi Y, Fujimoto Y, Masui T, Mizumoto M, et al. Impact of preoperative quality as well as quantity of skeletal muscle on survival after resection of pancreatic cancer. Surgery. 2015;157:1088-98.

Received: 7 February 2021 Accepted: 19 March 2021

Published online: 30 March 2021 
22. Shimada S, Sawada N, Ishiyama Y, Nakahara K, Maeda C, Mukai S, et al. Impact of obesity on short- and long-term outcomes of laparoscopy assisted distal gastrectomy for gastric cancer. Surg Endosc. 2018;32:358-66.

23. Saxton A, Velanovich V. Preoperative frailty and quality of life as predictors of postoperative complications. Ann Surg. 2011;253:1223-9.

24. Xue Q, Qin MZ, Jia J, Liu JP, Wang Y. Association between frailty and the cardio-ankle vascular index. Clin Interv Aging. 2019;14:735-42.

\section{Publisher's note}

Springer Nature remains neutral with regard to jurisdictional claims in published maps and institutional affiliations.
Ready to submit your research? Choose BMC and benefit from:

- fast, convenient online submission

- thorough peer review by experienced researchers in your field

- rapid publication on acceptance

- support for research data, including large and complex data types

- gold Open Access which fosters wider collaboration and increased citations

- maximum visibility for your research: over $100 \mathrm{M}$ website views per year

At BMC, research is always in progress.

Learn more biomedcentral.com/submissions 